\title{
Experimental and theoretical study on softening and pinching effects of bridge column
}

\author{
S. Wan ${ }^{\mathrm{a}, *}$, C.-H. Loh ${ }^{\mathrm{a}, \mathrm{b}}$, S.-Y. Peng ${ }^{\mathrm{a}}$ \\ ${ }^{\mathrm{a}}$ National Center for Research on Earthquake Engineering, Taipei, Taiwan, ROC \\ ${ }^{\mathrm{b}}$ Department of Civil Engineering, National Taiwan University, Taipei, Taiwan, ROC
}

Accepted 13 August 2000

\begin{abstract}
The goal of this study is to provide a better understanding on the behavior of pinching and softening effects for bridge column under earthquake loading. In the first part, a nonlinear cyclic loading test on a well-designed ductile RC bridge column was carried out experimentally. The hysteretic behavior of the bridge column was generated. In the second part, finite element analyses were used to predict the response under earthquake excitation. The hysteretic behavior obtained by experiment will be used as an input in material modeling for finite element programs. Discussions were made by using different computer codes to simulate the effects of pinching and softening of bridge column subjected to earthquake loading. Due to the inadequate functions of the element modeling, the theoretical system may underestimate the structural response under strong earthquake loading particularly on the prediction of softening and pinching effects. C 2001 Elsevier Science Ltd. All rights reserved.
\end{abstract}

Keywords: Pinching; Softening; Hysteretic behavior; Finite element programs

\section{Introduction}

Bridges are one of the important lifeline systems in a metropolitan area, which play a vital role after a strong earthquake in ensuring that emergency access to devastated areas to remove victims and to provide disaster relief. From the past studies and observations, bridge columns are the most vulnerable component during earthquake loading. Based on the damage data of Northridge earthquake and Kobe earthquake, the existing reinforced bridge columns did not perform well during recent earthquakes. The seismic design approach currently in use on bridge design employs a "force design" concept. In this approach, the member seismic forces are determined from an elastic design response spectrum for a maximum earthquake. To account for inelastic behavior of member or structure, the design force for each component of the bridge are then obtained by dividing the elastic forces by a response modification factor.

Some of those gravity load-designed bridge columns may be a failure under earthquake loading due to non-ductile design before seismic code in effect. Several observations were made on the bridge failure after strong earthquake:

\footnotetext{
* Corresponding author. Tel.: +886-2-2632-6607; fax: +886-2-27322223.
}

- The case of shear cracking and bond slip of the reinforcement is commonly observed in reinforced concrete structure during cyclic loading. This is so called pinching effect.

- Due to large axial load the structure may have loss of stiffness or strength. This is the so-called softening effect.

- Shear failure may occur due to inadequate transverse reinforcement. The capacity of bridge column may require checking both on nominal bending moment and shear force demand. In this study, shear failure is not included.

The purpose of this paper is to examine the suitable model for the dynamic analysis of bridge column. When modeling the complex behavior of RC bridge column, some assumptions were considered.

1. Only bending moment of the bridge column is considered. Shear failure is excluded in this study.

2. The deformation capacity of the bridge column is obtained by cyclic loading test. In this study, through the experimental data of nonlinear cyclic-loading of bridge column, two major effects — pinching and softening were taken into account through IDARC program. Strength softening is used to define the reduction in component strength capacity under cyclic loading after 

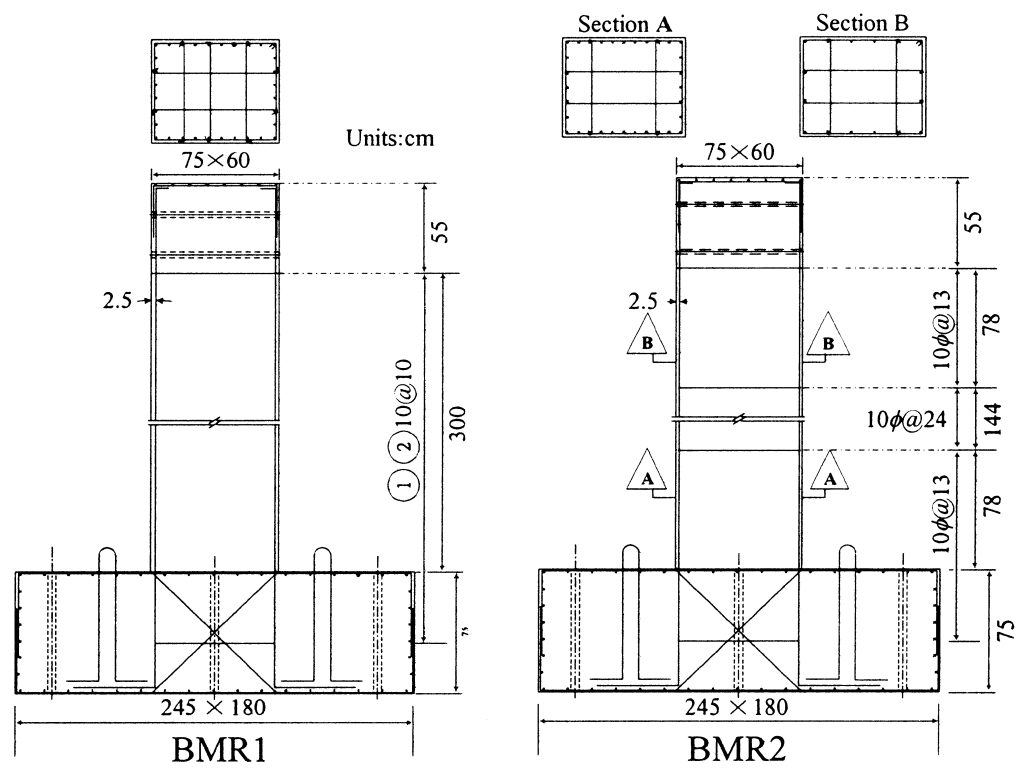

Fig. 1. Specimen detailing.

reaching the ultimate strength limit. Slip or pinching is used to define the ratio of retain stiffness to the initial stiffness on the unloading path. Comparison on the finite element modeling using ABAQUs program with idealized material behavior to simulate the seismic response of bridge column was shown. The significant discrepancies in the results based on different material modeling were discussed.

\section{Experimental study}

The cyclic loading test of bridge columns was carried out at the laboratory of National Center for Research on Earthquake Engineering (NCREE). Fig. 1 illustrates the dimension of the tested bridge column. Experimental investigations on the reinforced-concrete bridge column have been carried out to study the seismic performance of existing bridges in Taiwan. There are $242 / 5$-scaled models of bridge columns in the test program, 10 of them are rectangular columns, 10 are circular columns, and four are column-cap beam joints. The height of the scaled-down bridge column is $3.25 \mathrm{~m}$. The cross-section of the rectangular bridge column is $75 \times 60 \mathrm{~cm}^{2}$ while the cross-section of the circular column is $76 \mathrm{~cm}$ in diameter. BMR1 is a rectangular bridge column that is designed according to the 1995 version of Taiwan bridge design code. The longitudinal reinforcement consists of 32 No. 6 bars throughout all the height of the column. The shear reinforcement consists of No. 3 stirrups spacing at $10 \mathrm{~cm}$ with 135 and $90^{\circ}$ at the two ends, respectively. BMR2 is also a rectangular bridge column that is designed according to the 1987 version of Taiwan bridge design code. The longitudinal reinforcement consists of 32 No. 5 bars with half of the reinforcement terminated at the height of $180 \mathrm{~cm}$. The shear reinforcement consists of No. 3 stirrups that are two U-shaped stirrups lap spliced together. The spacing of the shear reinforcement is $13 \mathrm{~cm}$ at the plastic zone and $24 \mathrm{~cm}$ beyond the plastic zone.

The bridge column is mounted on the strong floor and the column is axially loaded by a pair of pretension tie rods through the cross beam at the top of the columns. An actuator is horizontally mounted on the reaction wall and cyclic load is applied laterally at the top of the column. Preliminary results of the tests are shown as follows.

BMRI-Column The axial load for the bridge column BMR1 is $940 \mathrm{kN}$. The steel ratio is $1.95 \%$. From the load-deformation relationship (Fig. 2), the maximum lateral load capacity of the column is $476 \mathrm{kN}$. At $80 \%$ of the ultimate lateral strength, the lateral displacement is $162.5 \mathrm{~cm}$. The bilinear yield displacement is measured about $24.3 \mathrm{~cm}$. The ductility ratio is 6.69 for BMR1column.

BMR2-Column The axial load for the bridge column BMR2 is also $940 \mathrm{kN}$. The steel ratio is $1.35 \%$. From the load-deformation relationship (Fig. 2), the maximum lateral load capacity of the column is $326 \mathrm{kN}$. At $80 \%$ of the ultimate lateral strength, the lateral displacement is $130 \mathrm{~cm}$ and bilinear yield displacement is $22.3 \mathrm{~cm}$. The ductility ratio is 5.83 for BMR2-column.

\section{Finite element study}

To study the behavior of bridge column under earthquake excitation loading, the numerical modeling of the bridge column was investigated. Finite element model with specified material properties was implemented. If the material modeling is incorrect, the calculation results of structural response such as displacement, velocity, and acceleration 


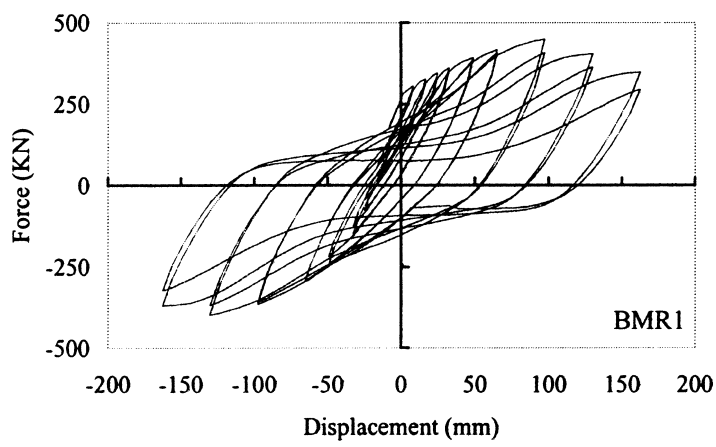

(BMR1)

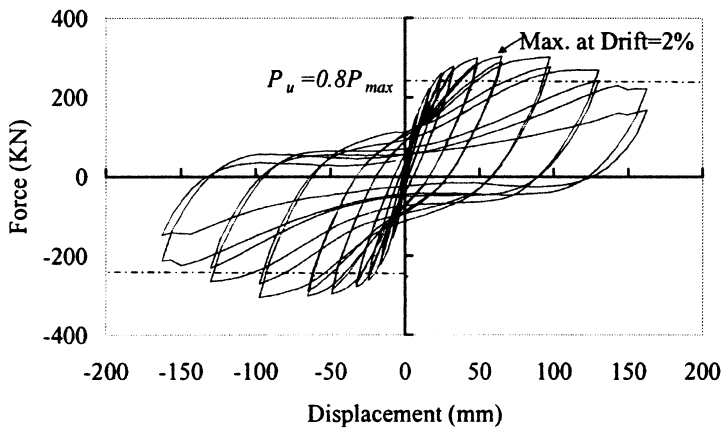

(BMR2)

Fig. 2. Load-deformation curve for BMR1 and BMR2 columns.

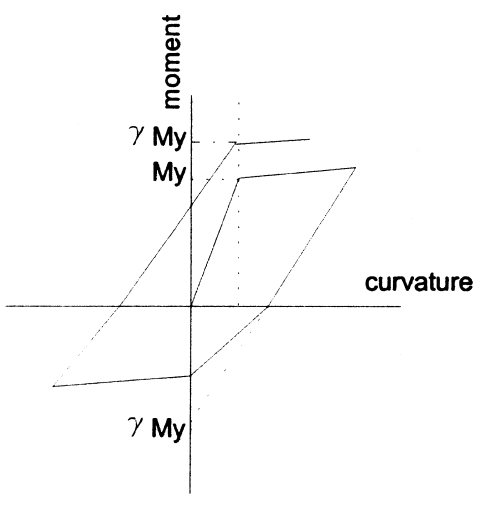

(a) Stiffness degradation

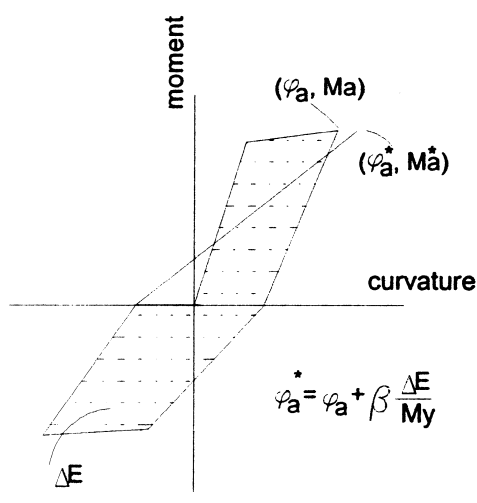

(c) Strength deterioration

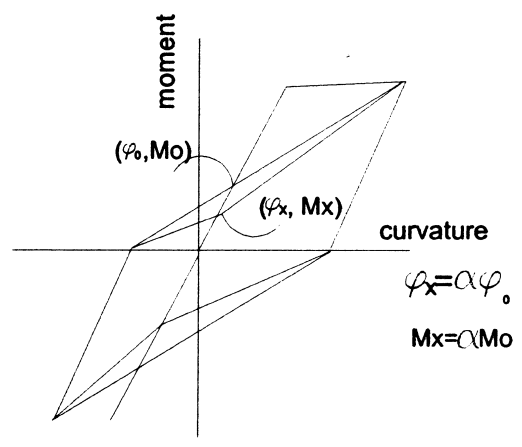

(b) Pinching

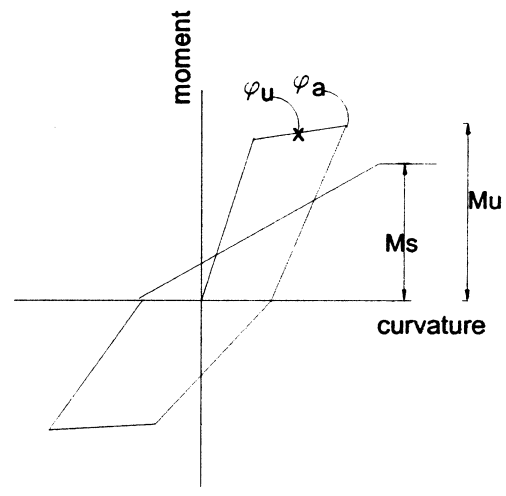

(d) Softening

Fig. 3. Hysteretic modeling of the moment curvature relationship (adopted from A. Ghobarah et al.).

cannot be measured correctly. Based on the hysteretic loop of the cyclic load test of the bridge column, a generalpurpose versatile model with four hysteretic control parameters - stiffness degradation, pinching, strength deterioration and softening ([1]). Fig. 3 presents the proposed hysteretic rules for moment curvature relationship of $\mathrm{RC}$ members. The model properties are defined as follows:

(1) The stiffness degradation is introduced by setting a common at this point until they reach the horizontal axis, as shown in Fig. 3(a). The parameter $\gamma$ indicates the degree of stiffness degradation which is proposed by [2]. The value of $\gamma$ varies from 1.0 to 10.0 , where 1.0 presents a high stiffness degradation and a value of 10.0 presents a negligible stiffness degradation.

(2) The pinching effect is introduced in the loops as shown in Fig. 3(b). The control parameter $\alpha$ which performs the reloading behavior in the hysteretic loop is 


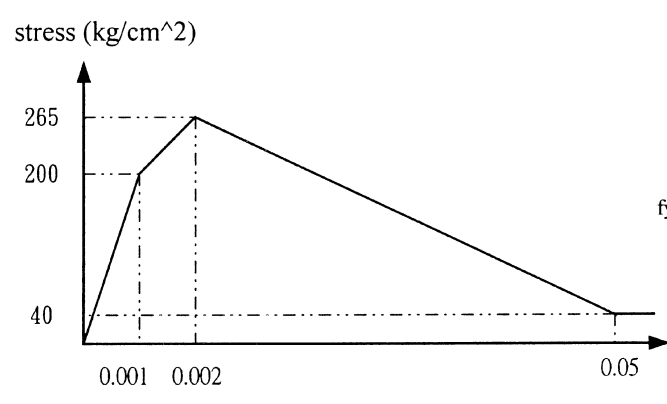

(1) Concrete

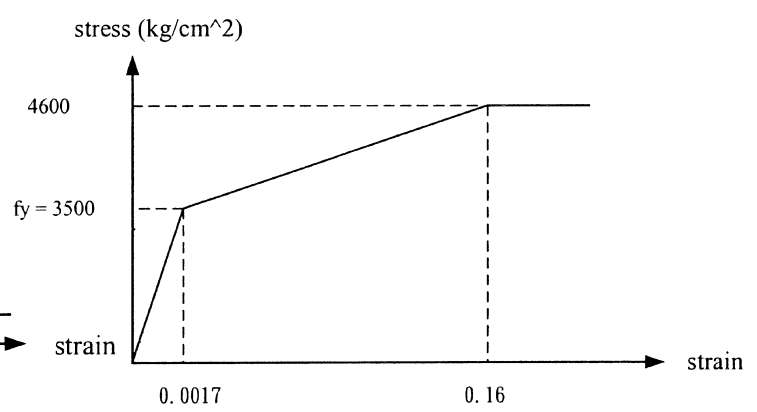

(2) Reinforcement

Fig. 4. Material properties on concrete and reinforcement (not drawn in scale).

proposed by [3]. The reloading branch is subdivided into two segments. The first segment aims at the crack closing point $\left(\phi_{\mathrm{x}}, M_{\mathrm{x}}\right)$ and the second segment starts from $\left(\phi_{\mathrm{x}}\right.$, $\left.M_{\mathrm{x}}\right)$ and aims at $\left(\phi_{\mathrm{a}}, M_{\mathrm{a}}\right)$. The parameter $\alpha$ governs the position of the crack closing point. The value of $\alpha$ may vary between 0.0 (high pinching) and 1.0 (no pinching). (3) The strength deterioration is introduced in the loops by specifying the point at which the reloading branch is aiming. This point may vary from the point at which unloading started in the previous cycle. A control parameter $\beta$ governs the strength deterioration ([2]). Fig. 3(c) illustrates the strength deterioration. Eq. (1) produces the relationship $\phi_{\mathrm{a}}^{*}$ and $\beta$ :

$\phi_{\mathrm{a}}^{*}=\phi_{\mathrm{a}}+\beta \frac{\Delta E}{M_{\mathrm{y}}}$

where $E$ is the incremental dissipated energy and $\phi_{\mathrm{a}}^{*}$ the curvature of the new targeted point. Introducing this parameter results in a reduced strength at the maximum attained deformation level $\phi_{\mathrm{a}}$. However, with increasing deformation beyond $\phi_{\mathrm{a}}$, the strength increases until it reaches the original moment-curvature envelope at point $\left(\phi_{\mathrm{a}}^{*}, M_{\mathrm{a}}^{*}\right)$. A typical value of $\beta$ varied between 0.0 (no strength deterioration) and 0.2 (ultimate strength deterioration).

(4) The softening behavior in the post-elastic range as in the model illustrated by Fig. 3(d) ([4]). An additional softening parameter $\eta$ is introduced in Eq. (2), and defined as:

$M_{\mathrm{s}}=M_{\mathrm{u}}(1-\eta \lambda)$

where $M_{\mathrm{s}}$ is the reduced moment capacity, $M_{\mathrm{u}}$ the ultimate moment, and $\lambda$ the ductility factor defined as

$\lambda=\frac{\phi_{\mathrm{a}}-\phi_{\mathrm{u}}}{\phi_{\mathrm{y}}}$

where $\phi_{\mathrm{a}}$ is the curvature at maximum moment, $\phi_{\mathrm{u}}$ the maximum curvature reached $\left(\phi_{\mathrm{a}}>\phi_{\mathrm{u}}\right)$ and $\phi_{\mathrm{y}}$ the curvature at yield. The value of $\eta$ varies from 0.0 to 0.5 , where a value of 0.5 signifies rapid strength softening after the ultimate point and 0.0 signifies that there is no softening.
A residual moment $M_{\mathrm{r}}$ can also be specified if desired. This means that bending moment capacity will not be less than $M_{\mathrm{r}}$. The strength softening hysteretic relationship has shown in Fig. 3(d).

For the purpose of improving the result accuracy, a computer program was developed to solve four parameters $(\alpha, \beta, \gamma, \eta)$ in a hysteretic model. According to the experimental data, force-displacement relationship was converted to moment-curvature relationship. Then it can automatically calculate all the parameters. Based on the experimental data of the BMR2 bridge column, parameters of the hysteretic model are identified as $\alpha=0.356, \beta=0.011$, $\gamma=2.83, \eta=0.097$. Later, this set of parameter was plugged into IDARC 5.0 computer code to consider the softening and pinching effect of bridge column.

On the other hand, the computer program ABAQUS-5.7 was also used to investigate the bridge column subjected to an earthquake. Beam element was selected to simulate the bridge column. Fig. 4 illustrates the material properties for concrete and reinforcement. The extension line (after $f_{c}^{\prime}=265 \mathrm{~kg} / \mathrm{cm}^{2}$ ) on Fig. 4(a) was used to simulate the stress strain relationship of confined concrete. Beam element (B33: see ABAQUS manual) was selected to analyze the problem. Due to the limitation of using beam element in simulation of the pinching and softening effects, the structural response will be compared with the results using IDARC program. The discrepancy between considering and ignoring the softening and pinching effect on strong and weak earthquake loadings are discussed.

Through these analysis, the following results can be discussed: (1) static analysis by using cyclic-loading as input; and (2) dynamic analysis by using recorded earthquakes as input, for considering/ignoring softening and pinching effects.

\subsection{Static analysis: cyclic-loading test}

In numerical simulation, the displacement control scheme was used to generate hysteretic behavior of the column. A step-by-step procedure in increasing the displacement to reach the maximum displacement capacity (about 


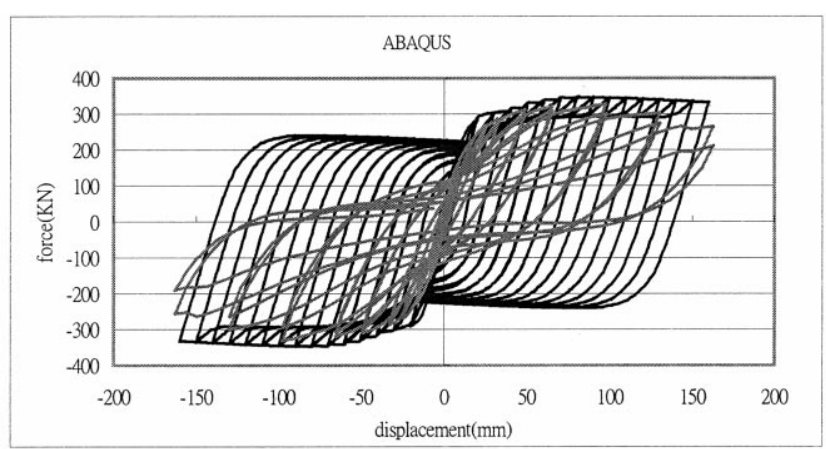

(a) ABAQUS

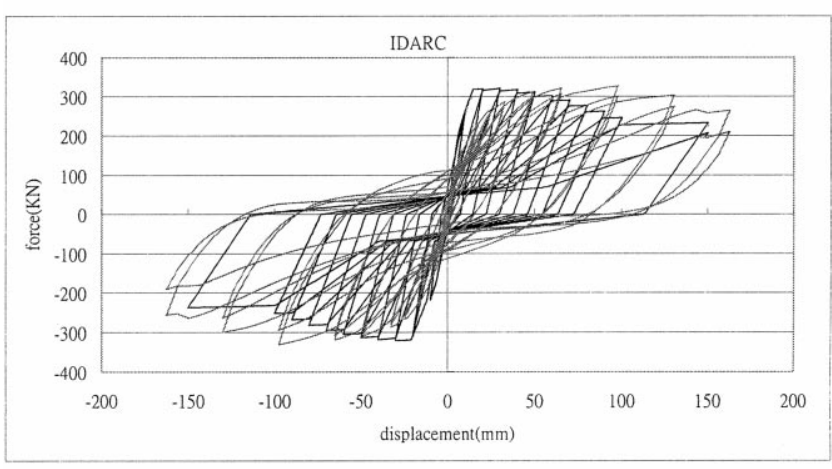

(b) IDARC

Fig. 5. Comparison between the experimental and analytical hysteretic loop of bridge column (a) ABAQUS and (b) IDARC.

$150 \mathrm{~mm}$ ) obtained from nonlinear push-over test. Fig. 5(a) and (b) illustrates the hysteretic behavior of the column obtained from ABAQUS and IDARC program, respectively. The comparison on the hysteresis loop between numerical calculation and test result is shown. For instances, the gray line presents the data from experimental studies, the black line presents the simulation from ABAQUS and IDARC, respectively.

From the cyclic loading test, it can be clearly observed that the results obtained from ABAQUs can find the strength envelope (or capacity curve) precisely. But, when the deformation increases, the area under the loop varies dramatically. On the contrary, the result from IDARC can simulate the hysteretic behavior much better than ABAQUS, especially in large deformation. Comparison on the hysteretic dissipated energy was also made between analytical and experimental result. The areas under the curve were listed in Table 1 . When the deformation is small, the differences shown on the hysteretic energy in computer simulation (either using ABAQUS or IDARC programs) and experimental study is small. From this study, it is found that by using numerical simulation to study the dynamic response of bridge column, IDARC program can take both pinching and softening effect into
Table 1

The area under hysteretic loop $(\mathrm{kN}-\mathrm{mm})$ for cyclic loading

\begin{tabular}{llc}
\hline Computer program & $\begin{array}{l}\text { Small deformation } \\
(30 \mathrm{~mm})\end{array}$ & $\begin{array}{l}\text { Large deformation } \\
(150 \mathrm{~mm})\end{array}$ \\
\hline ABAQUS & 20917 & 144698 \\
IDARC & 18615 & 60491 \\
Experiment & 17919 & 46047 \\
\hline
\end{tabular}

account in the case of large deformation. The hysteretic loop looks closer using IDARC program than using ABAQUS program. By using ABAQUS program, the beam element was used to simulate the column behavior, however, this type of element cannot reflect the pinching and softening effects, then the simulation of the bridge column under an earthquake will induce significant error. This may imply that in large earthquake, pinching and softening effect may play a vital role for bridge column safety.

\subsection{Dynamic analysis}

In this study, a ground motion time history was selected as an input to study the dynamic response of this bridge column under an earthquake excitation. This ground motion time history CWB001 (with PAG $=0.167 g$ ) was recorded in 1991, March 12, Tainan, Taiwan. The moment magnitude is about 5.67. To understand the dynamic response of column with and without considering softening and pinching effect under different excitation intensities of PGA level is normalized as $0.2,0.3,0.4 g$, respectively. Fig. 6 presents the simulation of force-displacement behavior for smallintensity level of earthquake excitation from IDARC and ABAQUS program. Fig. 7 shows the simulation of forcedisplacement behavior for large-intensity level of earthquake excitation from IDARC and ABAQUS. Table 2 summarizes the result of maximum displacement under the same ground excitation. The maximum acceleration was obtained by increasing the PGA value $0.01 g$ step-bystep until the bridge column failure.

Fig. 8 shows the relative acceleration response (timehistory) at the top of the bridge column for small-level of

Table 2

Maximum displacement of bridge column calculated by ABAQUS and IDARC program

\begin{tabular}{lll}
\hline & \multicolumn{2}{l}{ CWB001 } \\
\cline { 2 - 3 } $\begin{array}{ll}\text { Computer } \\
\text { programs }\end{array}$ & ABAQUS & IDARC \\
\hline $\begin{array}{lll}\text { Normalized } \\
\text { acceleration }\end{array}$ & $\begin{array}{l}\text { Max displacement } \\
(\mathrm{mm})\end{array}$ & $\begin{array}{l}\text { Max displacement } \\
(\mathrm{mm})\end{array}$ \\
\hline $0.2 g$ & 17.6 & 12.9 \\
$0.3 g$ & 20.1 & 14.7 \\
$0.4 g$ & 22.1 & 19.4 \\
$0.5 g$ & $\mathrm{XXX}$ & 24.6 \\
Max acceleration & $0.43 g$ & $0.58 g$ \\
\hline
\end{tabular}



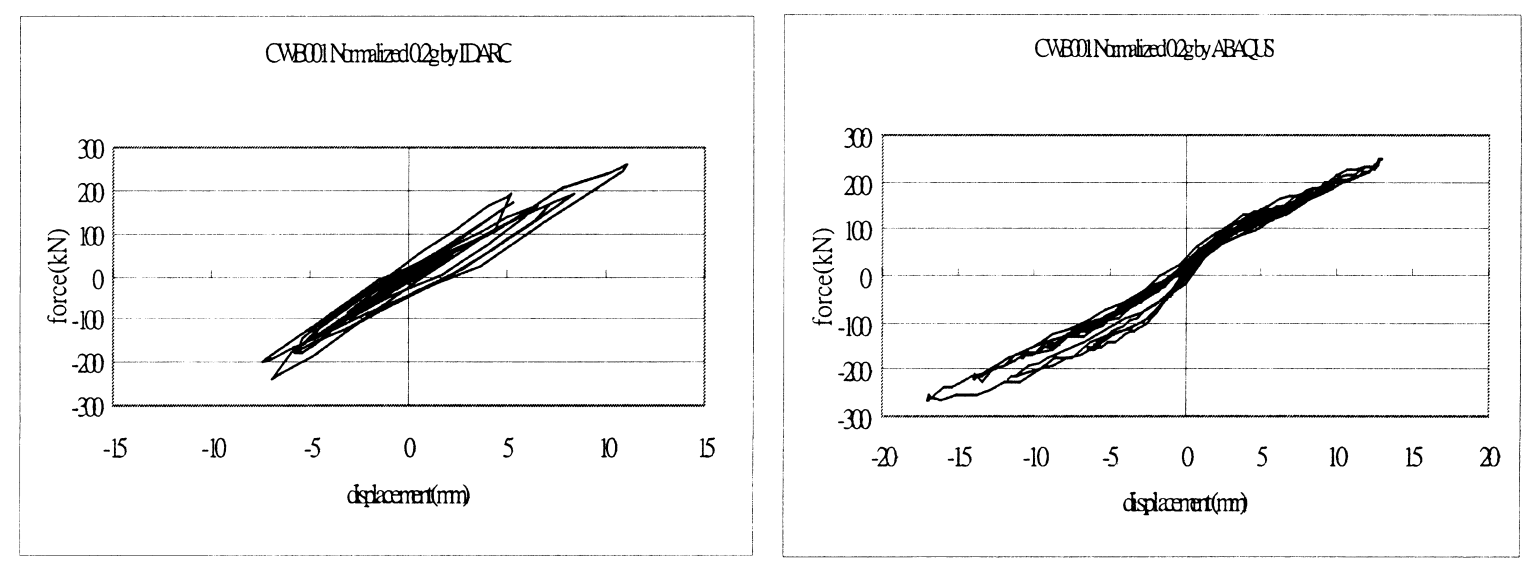

Fig. 6. Simulation of hysteresis loop low-level of input motion $(0.2 g)$.
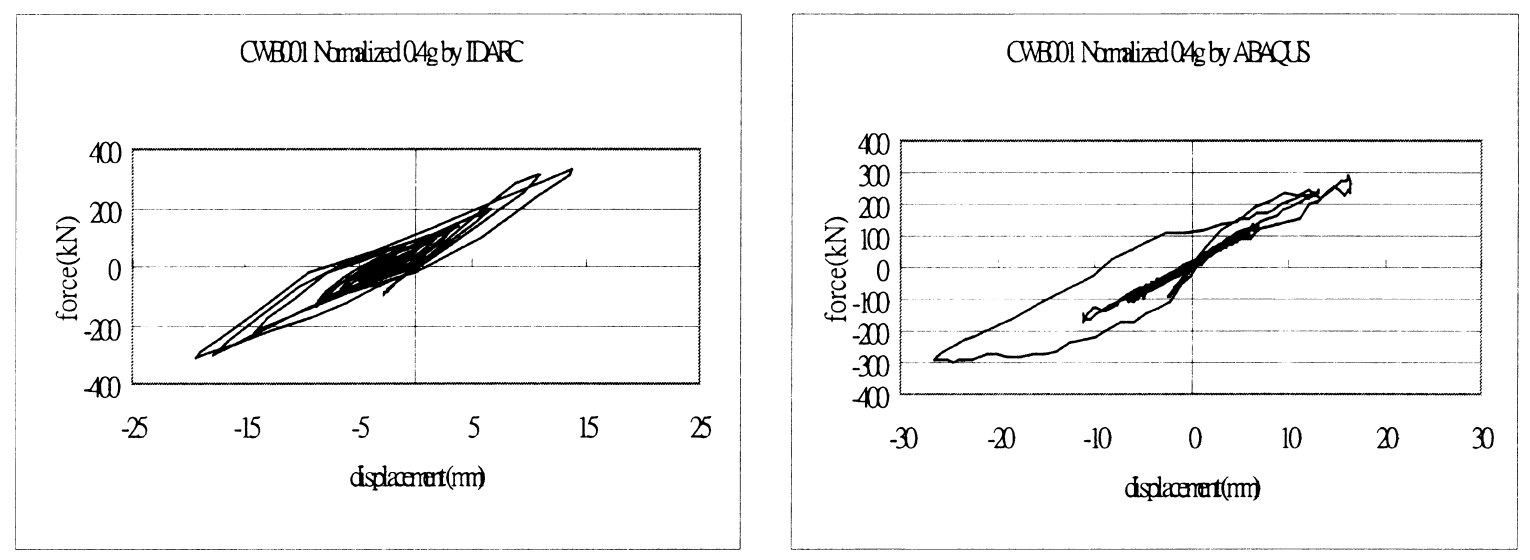

Fig. 7. Simulation of hysteresis loop large-level of input motion earthquake $(0.4 g)$.
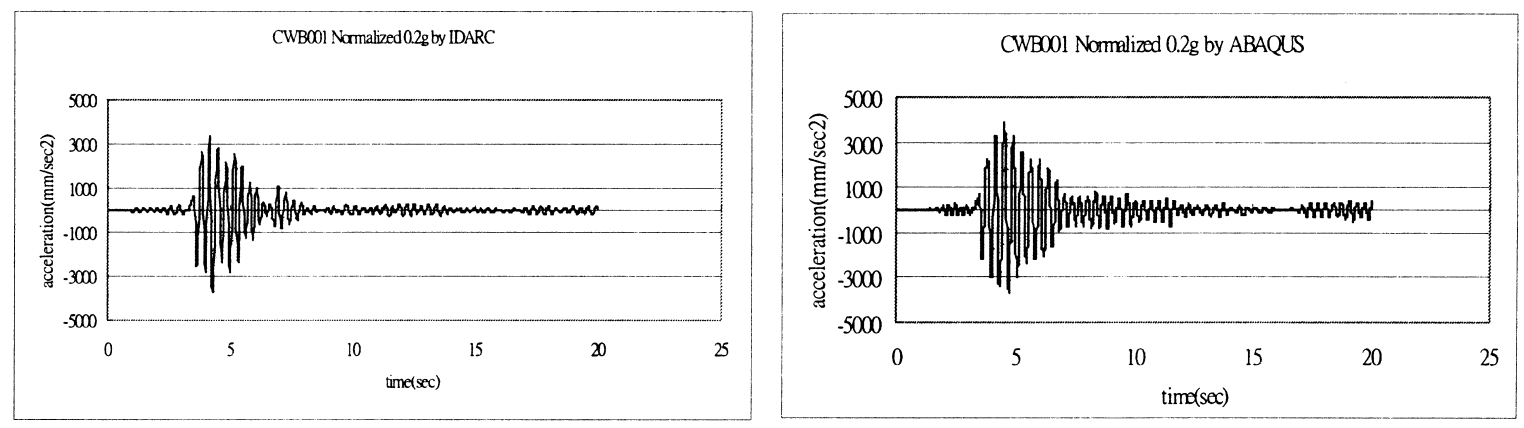

Fig. 8. Acceleration on the top of the column for $0.2 g$.

earthquake excitation and Fig. 9 shows the acceleration (time-history) at the top of the structure for large-level of earthquake excitation. Comparison on the prediction of maximum acceleration at the top of the column is shown in Table 3.

Based on the previous study, it can be observed that IDARC program provides a smaller hysteretic loop (see Fig. 8) than ABAQUS. From the concept of energy conservation, the kinetic energy computed though IDARC will be larger than through ABAQUS. In other word,
ABAQUS may underestimate the response by neglecting the effect of softening and pinching.

Table 4 presents maximum acceleration at the top of the bridge column using IDARC program to compute softening and pinching effect. Several cases were made to verify the effects of pinching and softening. Case 1 is ignoring pinching by taking the parameter $\alpha$ as 1.0. Case 2 is ignoring softening by taking the parameter $\eta$ and $\beta$ as 0.0 . Case 3 is ignoring both effects and Case 4 takes both effects into account. 

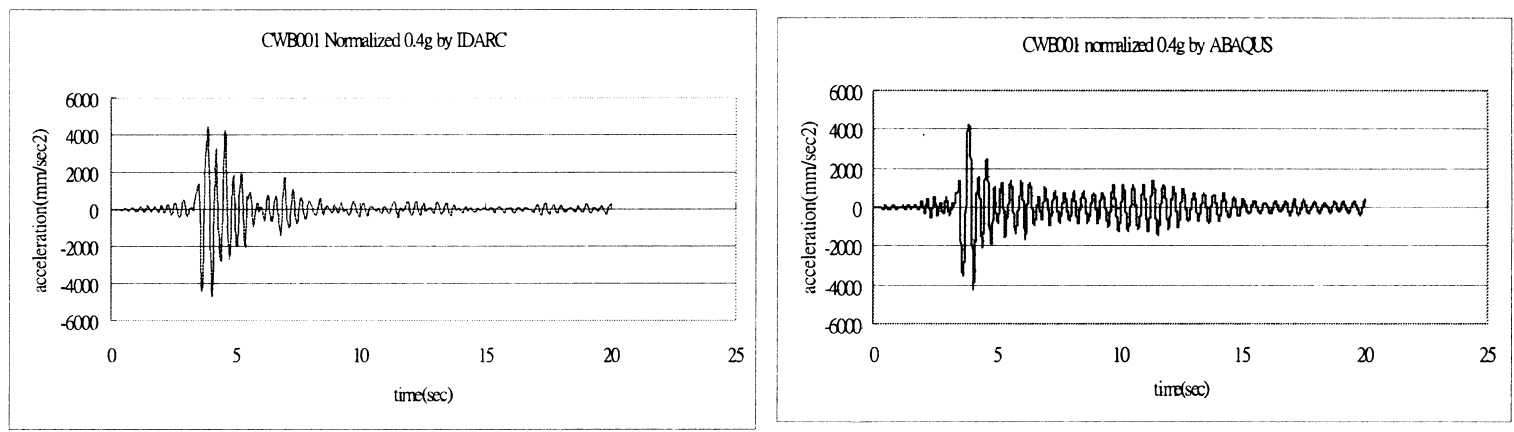

Fig. 9. Acceleration on the top of the column for $0.4 g$.

It was found out that the case with ignoring pinching and softening will cause a great deal of difference in computing structural response at high PGA level. The softening effect seems to be a dominant factor for bridge column response under an earthquake.

\section{Summary and conclusion}

The goal for this study is to develop a computer code on the dynamic analysis of bridge column, which induces softening and pinching effect. Based on the result of experimental study, the hysteretic model of bridge column was obtained by using cyclic loading data. Then, the material properties of parameters $(\alpha, \beta, \gamma, \eta)$ were used to calculate the earthquake result. On the other hand, an element-based computer code (ABAQUS) was also used to simulate the behavior of bridge column under an earthquake. The following observations are made:

Table 3

Maximum acceleration at the top of the column

\begin{tabular}{lll}
\hline $\begin{array}{l}\text { Computer } \\
\text { programs }\end{array}$ & $\begin{array}{l}\text { CWB001 } \\
\text { ABAQUS }\end{array}$ & IDARC \\
\hline $\begin{array}{l}\text { Normalized } \\
\text { acceleration }\end{array}$ & $\begin{array}{l}\text { Max acceleration } \\
\left(\mathrm{mm} / \mathrm{s}^{2}\right)\end{array}$ & $\begin{array}{l}\text { Max acceleration } \\
\left(\mathrm{mm} / \mathrm{s}^{2}\right)\end{array}$ \\
\hline $0.2 g$ & 3888 & 3682 \\
$0.3 g$ & 3994 & 4090 \\
$0.4 g$ & 4121 & 4755 \\
$0.5 g$ & $\mathrm{XXX}$ & 4823 \\
\hline
\end{tabular}

Table 4

Maximum acceleration at the top of the column $\left(\mathrm{mm} / \mathrm{s}^{2}\right)$

\begin{tabular}{lllll}
\hline \multirow{2}{*}{ Ignoring } & $\begin{array}{l}\text { Case 1 } \\
\text { Pinching }\end{array}$ & $\begin{array}{l}\text { Case 2 } \\
\text { Softening }\end{array}$ & $\begin{array}{l}\text { Case 3 } \\
\text { Pinching + softening }\end{array}$ & $\begin{array}{l}\text { Case 4 } \\
\text { Nothing }\end{array}$ \\
\hline Normalized 0.2g & 3356 & 3397 & 3268 & 3682 \\
$0.3 g$ & 4062 & 3703 & 3620 & 4090 \\
$0.4 g$ & 4702 & 4445 & 4415 & 4755 \\
$0.5 g$ & 4781 & 4571 & 4473 & 4823 \\
\hline
\end{tabular}

- If the bridge column was designed to resist strong ground motion, it is recommended that softening effect cannot be ignored.

- IDARC program can simulate the dynamic characteristics of bridge column by using the cyclic loading result from the experimental study. But the hysteretic behavior can be accurately predicted as compared to the experimental study.

- ABAQUS provides better strength envelope on the capacity of bridge column, but the entire hysteretic loop cannot match the experimental data because of beam element, which cannot consider the softening and pinching effects.

- For large-scaled earthquake, it is recommended that pinching and softening cannot be neglected.

\section{Acknowledgements}

This research is jointly supported by the National Science Council (NSC89-2811-E002-0001) and the National Center for Research on Earthquake Engineering (NCREE). The experimental studies were carried out by Mr C.S. Chou of NCREE and the graduate students from National Taiwan University. Their contributions are greatly appreciated.

\section{References}

[1] Ghobarah A, Aziz T, Abou-Elfath H. Softening effect on the seismic response of non-ductile concrete frames. Journal of Earthquake Engineering 1999;3(1):59-81.

[2] Park Y, Reinhorn A, Kunnath S. IDARC: inelastic damage analysis of frame shear wall structures, Technical report NCEER-87-0008, Department of Civil Engineering. State University of New York at Buffalo, Buffalo, NY, 1987.

[3] Chung Y, Meyer C, Shinozuka M. Seismic damage assessment of reinforced concrete members. Report No. NCEER-87-0022, National Center for Earthquake Research, State University of New York at Buffalo, Buffalo, NY, 1987.

[4] Otani S. Nonlinear dynamic analysis of reinforced concrete building structures. Canadian Journal of Civil Engineering 1980;7:333-44. 